\title{
Influence of daylength on the initiation of the breeding season of the marsupial possum, Trichosurus vulpecula
}

\author{
R. T. Gemmell \\ Department of Anatomy, University of Queensland, St Lucia, Brisbane, Queensland 4067, Australia
}

\begin{abstract}
Summary. In Queensland, possums in the wild and in captivity first give birth during March and continue to give birth throughout the year until November. In this study the effect of short daylengths on the initiation of breeding activity was examined. One male and 4 female possums were transferred from an outside enclosure into a light control room ( $10 \mathrm{~h}$ light, $14 \mathrm{~h}$ dark) on 22 November. A control group of possums was housed in outside enclosures. The possums held in the light room gave birth $81.2 \pm$ 14.7 days (s.e.m.) after being placed in the short-day photoperiod. The control group gave birth $133.8 \pm 9.8$ days after 22 November. This result suggests that photoperiod plays a role in the initiation of the breeding season of the brushtail possum.
\end{abstract}

Keywords: seasonal breeding; short daylength; marsupial; brushtail possum; captivity

\section{Introduction}

The brushtail possum, Trichosurus vulpecula, exhibits an annual seasonality in breeding activity (Tyndale-Biscoe, 1955; Lyne \& Verhagen, 1957; Pilton \& Sharman, 1962; Dunnet, 1964; Gemmell ('t al., 1986, 1987). In Queensland, births were first observed during March and continued throughout the year until November; no births having been recorded during December, January and February (Gemmell, 1987; Gemmell et al., 1987). The rate of change of daylength has been suggested to play an important role in determining the start of the breeding season in the possum. However, the variation in the start of the breeding season, depending on location, would suggest that factors other than photoperiod may influence reproductive activity (Gemmell et al., 1986; Gemmell, 1987).

There have been many studies of eutherians in which the effect of photoperiod on breeding activity has been examined. Eutherian mammals which mate in spring and summer are termed long-day breeders, for example, cats (Dawson, 1941) and mares (Burkhardt, 1947). Eutherians such as the sheep (Legan \& Karsch, 1980; Wayne et al., 1988) and red deer (Webster \& Barrell, 1985) which mate in winter are short-day breeders. Movement of long-day breeders from a short-day to a long-day pattern stimulates ovulation and, similarly, a short-day pattern stimulates a short-day breeding animal.

Although there is a wide range of eutherian mammals in which the effect of photoperiod has been examined, similar studies have not been carried out with marsupials. Godfrey (1969) and Smith et al. (1978) demonstrated that a long-day photoperiod stimulated oestrous activity in Sminthopsis crassicaudata in April and May. This dasyurid normally mates in June. Only one other marsupial has been subjected to changes in daylength. The effect of photoperiod on breeding activity has been studied in the tammar wallaby (Macropus eugenii) and Bennett's wallaby (Macropus rufogriseus). These marsupials exhibit embryonic diapause and daylength can influence the reactivation of the corpus luteum and the continued development of the fetus: increasing or long daylengths prevent reactivation whereas decreasing or short daylengths permit the response (TyndaleBiscoe \& Renfree, 1987; Loudon \& Curlewis, 1987). The manipulation of daylength affects the corpus lutuem rather than stimulating an early ovulation via the hypothalamus and pituitary. 
In the present study, the effect of a short daylength ( $10 \mathrm{~h}$ light, $14 \mathrm{~h}$ dark) on the initiation of breeding activity of the possum was examined. This marsupial normally gives birth in late autumn and winter and this light regimen from December through to March should stimulate ovulation and pregnancy in months normally associated with anoestrus.

\section{Materials and Methods}

Eleven adult female possums were used in this study. Seven possums with one adult male were housed in a fully enclosed holding yard, $9 \times 3 \times 2 \mathrm{~m}$, and were supplied with running water, fruit and vegetables. The major portion of this yard was open and the possums were thus kept in a natural photoperiod. The remaining 4 adult female possums were transferred from a similar outside enclosed holding yard to a light-controlled room on 22 November 1988 when the daylength was $13.34 \mathrm{~h}$. The light-controlled room was $3 \times 3 \times 4 \mathrm{~m}$ and the 4 females and 1 male were supplied with water, fruit and vegetables. Light was supplied by one $40-\mathrm{W}$ fluorescent tube. The level of illuminance measured from light reflected from the walls was $140( \pm 15$, s.e.m., $n=6)$ lux. Light levels were determined with a National Digital Lux tester, Matsushita Electric Industrial Co. Ltd, Tokyo, Japan. Lights on was at 07:00 h and off at 17:00 h (10 h light, $14 \mathrm{~h}$ dark). The room had separate air intake and exhaust ducts which were baffled to prevent light leaks. Temperature was not controlled.

Blood samples were obtained weekly from 9 possums ( 2 control possums were not blood sampled), until a young was first observed in the pouch. The size and morphology of the teats of the females were noted as these enlarge close to parturition. The date of birth of pouch young was determined by observing the day of birth or estimating the age of pouch young from the length of the head and the total body weight according to the method described by Lyne \& Verhagen (1957).

Progesterone concentrations in plasma were determined by radioimmunoassay using the method described previously (Gemmell et al., 1987) using sheep anti-progesterone-11-hemisuccinate-bovine serum albumin (Antiserum No. 334) kindly donated by Dr R. I. Cox, CSIRO, Prospect, New South Wales, Australia. The antiserum was highly specific for progesterone, the only significant cross-reaction being with $11 \beta$-hydroxyprogesterone $(1 \mathrm{I} \cdot 9 \%)$. The limit of the sensitivity of the assay was $25 \mathrm{pg} /$ tube and the intra- and inter-assay coefficients of variation were $12.5 \%(n=5)$ and $14.0 \%(n=10)$ respectively. The assay buffer blank was $<0.1 \mathrm{ng} / \mathrm{ml}$ and the efficiency of extraction was $87.0 \%$ $(n=10)$.

\section{Results}

Two of the control possums, which were blood sampled weekly, gave birth on 4 and 10 April (Fig. 1). Two of the control possums, which were not blood sampled, gave birth on 9 March and 25 April. Progesterone profiles indicative of an oestrous cycle were observed in the 3 remaining control possums during March and April (Fig. 1a). These 3 possums which were housed in the same enclosure with 1 male possum were transferred to other enclosures where they subsequently gave birth in May and June. The 4 possums housed in a natural photoperiod gave birth $133 \cdot 3 \pm 9 \cdot 8$ days from the start of the experiment, 107, 133, 139 and 154 days from 22 November 1988.

The 4 possums housed in a short-day photoperiod gave birth on 11 and 30 January, 17 February and 21 March (Fig. 1b), 81.2 \pm 14.7 days (s.e.m.) from the start of the experiment. The plasma progesterone profile of the possum which gave birth on 21 March indicated that an oestrous cycle occurred during February (Fig. 1b). Births in the 4 possums held in a short-day photoperiod were observed 50,69, 87 and 119 days from 22 November, 1988.

\section{Discussion}

The short-day photoperiod initiated ovulation and pregnancy in the possum in a period of the year when the possum is normally in anoestrus.

In the captive colony of possums housed in the natural photoperiod, the range of first births of the season was from 9 March to 25 April, 47 days during 1989. The birth dates of the 3 control possums, which showed cyclic activity during March and April, were not used in this calculation. The range observed in 1989 was similar to those obtained during the previous 5 years (Table 1). The mean range of first births of the season was $24.4 \pm 6.6$ days over 7 years. The range for the 4 


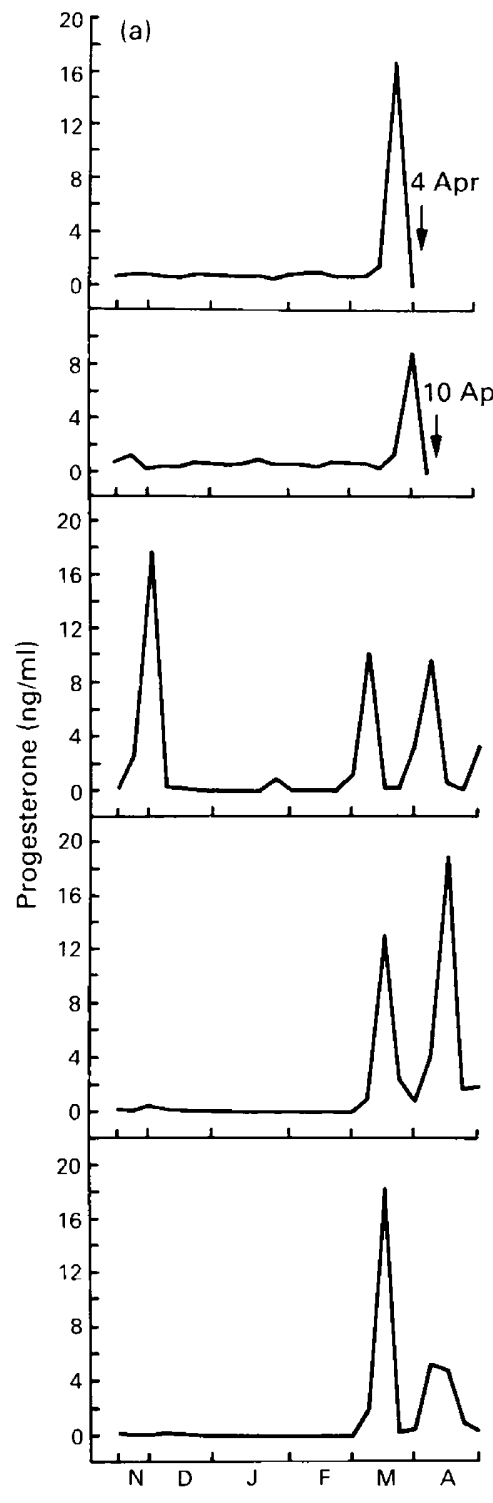

(b)

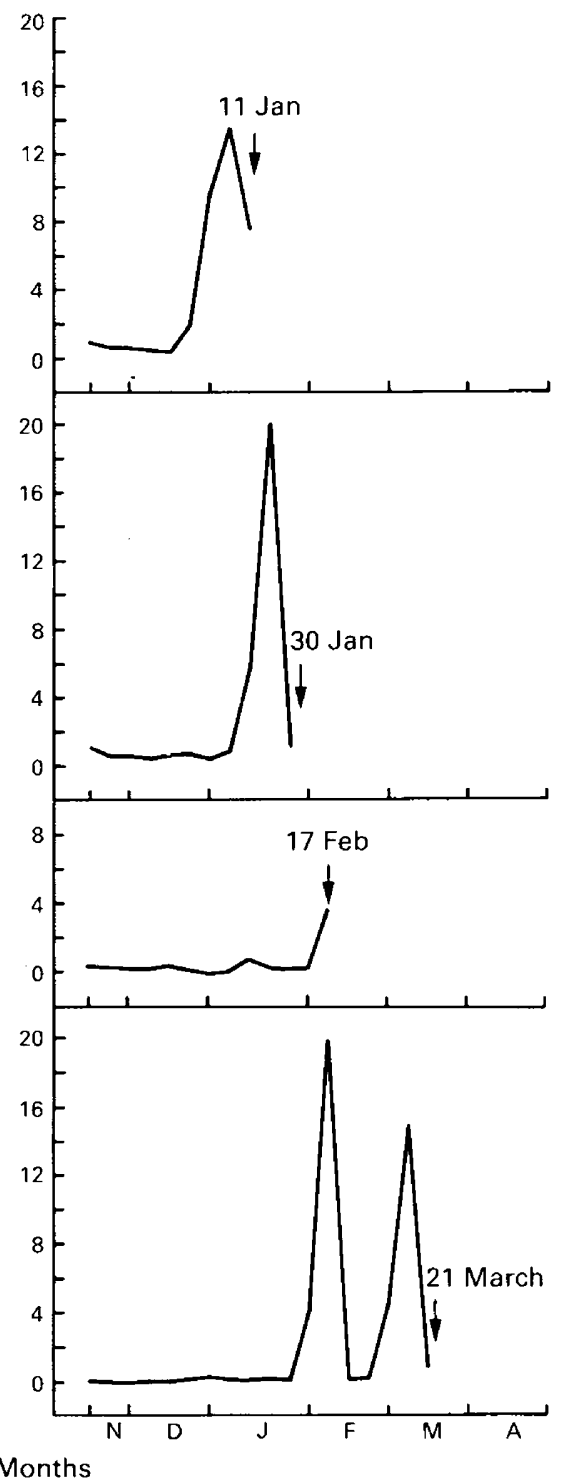

Fig. 1. Plasma progesterone profiles of (a) 5 possums housed in a natural photoperiod and (b) 4 possums transferred to a photoperiod of $10 \mathrm{~h}$ dark, $14 \mathrm{~h}$ light on 22 November. The date of birth is indicated for 6 of the possums.

possums stimulated to breed in the non-breeding period of the year was 69 days. The range of first births of the season in the possums housed in natural photoperiod compared with those in the artificial photoperiod, 47 and 69 days respectively, are similar. The range of first births would have been closer if the possum which gave birth on 21 March had become pregnant during the first cycle of the season. Evidence of an oestrous cycle before the increase in plasma progesterone of pregnancy has been reported previously in possums (Fig. 1; Gemmell, 1987).

The number of days from the start of the short-day photoperiod until ovulation varies between species; 49-55 days for sheep (Legan \& Karsch, 1980; Wayne et al., 1988), $75 \pm 2.3$ days for red 
Table 1. First births of the breeding season for brush tailed possums

\begin{tabular}{cccc}
\hline Year & Range & Days & No. of possums \\
\hline 1983 & 30 March-3 April & 4 & 2 \\
1984 & 11 March-30 March & 17 & 7 \\
1985 & 24 March-9 April & 16 & 4 \\
1986 & 31 March-12 April & 12 & 4 \\
1987 & 14 March-31 April & 49 & 5 \\
1988 & 16 March-9 April & 26 & 8 \\
1989 & 9 March-25 April & 47 & 4 \\
\hline
\end{tabular}

Mean range of first births of the breeding season $=24 \cdot 4 \pm 6 \cdot 6$ days (s.e.m.), range 9 March to 31 April.

deer (Webster \& Barrell, 1985) and $64 \pm 14 \cdot 7$ days for the possum (gestation period 17.5 days). A similar time interval is observed for mammals which mate in summer when housed in a long-day photoperiod; 37-100 days for cats (Dawson, 1941), 38-63 days for mares, 38-64 days for ferrets (Bissonette, 1932) and 35-77 days for the marsupial dasyurid, Sminthopsis crassicaudata (Godfrey, 1969). There would appear to be a requirement of approximately 50 days for the ovary to be primed for ovulation. The large range in response between animals of each species would suggest that the efficiency of this stimulus is variable.

Although photoperiod is involved in the control of seasonal breeding in the possum, the large variation in breeding seasons throughout Australia (Gemmell et al., 1987) suggests that other environmental variables are involved in the initiation of the breeding season in the brushtail possum in the wild.

I thank the Australian Research Council for financial assistance.

\section{References}

Bissonette, T.H. (1932) Modifications of mammalian sexual cycles; reactions of ferrets (Putorius vulgaris) of both sexes to electric light added after dark in November and December. Proc. R. Soc. B110, 322--336.

Burkhardt, J. (1947) Transition from anoestrus in the mare and the effects of artificial lighting. J. agric. Sci., Camb. 37, 64-68.

Dawson, A.B. (1941) Early estrus in the cat following increased illumination. Endocrinology 28, 907-910.

Dunnet, G.M. (1964) A field study of local populations of brush-tailed possum Trichosurus vulpecula in eastern Australia. Proc. R. Soc. 142, 665-669.

Gemmell, R.T. (1987) Effect of melatonin and removal of pouch young on the seasonality of births in the marsupial possum, Trichosurus vulpecula. J. Reprod. Fert. 80, 301-307.

Gemmell, R.T., Cepon, G. \& Barnes, A. (1986) Weekly variations in weight and plasma testosterone concentrations in the captive male possum, Trichosurus vulpecula. Gen. comp. Endocr. 62, 1-7.

Gemmell, R.T., Hughes, R.L. \& Jenkin, G. (1987) Comparative studies on the hormonal profiles of progesterone and prostaglandin $F$ metabolite in the possum, Trichosurus vulpecula. In Possums and Opossums, Studies in Evolution, pp. 279-291. Ed. M. Archer. Royal Zoological Society of New South Wales and Surrey Beatty and Sons, Sydney.
Godfrey, G.K. (1969) The influence of increased photoperiod on reproduction in the dasyurid marsupial, Sminthopsis crassicaudata. J. Mammal. 50, 132-133.

Legan, S.J. \& Karsch, F.J. (1980) Photoperiodic control of seasonal breeding in ewes: modulation of the negative feedback action of estradiol. Biol. Reprod. 23, 1061-1068.

Loudon, A.S.I. \& Curlewis, J.D. (1987) Refractoriness to melatonin and short daylengths in early seasonal quiescence in the Bennett's wallaby (Macropus rufogriseus rufogriseus). J. Reprod. Fert. 81, 543-552.

Lyne, A.G. \& Verhagen, A.M.W. (1957) Growth of the marsupial Trichosurus vulpecula and a comparison with some higher mammals. Growth 21, 167-195.

Pilton, P.E. \& Sharman, G.B. (1962) Reproduction in the marsupial Trichosurus vulpecula. J. Endocr. 25, 119-136.

Smith, P.J., Bennett, H.J. \& Chesson, C.M. (1978) Photoperiod and some other factors affecting reproduction of female Sminthopsis crassicaudata (Gould) (Marsupialia: Dasyuridae). Aust.J. Zool. 26, 449-463.

Tyndale-Biscoe, C.H. (1955) Observations on the reproduction and ecology of the brush-tail possum Trichosurus vulpecula Kerr (Marsupialia) in New Zealand. Aust. J. Zool. 3, 162-184.

Tyndale-Biscoe, H. \& Renfree, M. (1987) Reproductive Physiology of Marsupials. Cambridge University Press, Cambridge. 
Wayne, N.L., Malpaux, B. \& Karsch, F.J. (1988) How does melatonin code for daylength in the ewe: duration of noctural melatonin release or coincidence of melatonin with a light-entrained sensitive period? Biol. Reprod. 39, 66-75.

Webster, J.R. \& Barrell, G.K. (1985) Advancement of reproductive activity, seasonal reduction in prolactin secretion and season pelage changes in pubertal red deer hinds (Cervus elaphus) subjected to artificially shortened daily photoperiods or daily melatonin treatments. J. Reprod. Fert. 73, 255-260.

Received 17 July 1989 